\author{
Military Technical College \\ Kobry El-Kobba \\ Cairo, Egypt
}

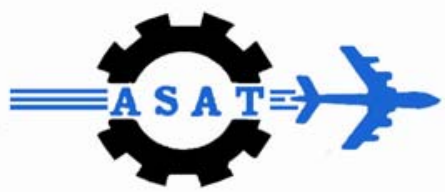

12-th International Conference on

Aerospace Sciences \& Aviation Technology

\title{
INVESTIGATION OF HARDWARE-IN-LOOP SIMULATION (HILS) FOR GUIDANCE AND CONTROL SYSTEM
}

\author{
Elhalwagy* Y. Z., Abdelhady** A.M. and Fahmy*** A.E.
}

\begin{abstract}
Classical guidance and control laws have been used for aerospace vehicles, which are aerodynamically unstable and non-linear, with varying degrees of performance, complexity and seeker/sensor requirements. Accuracy requirements with dynamic tactics of modern warfare demand performance improvement, which is a trade-off between costly sophisticated hardware and computationally intensive software.

Flight motion simulator (FMS) is a high-bandwidth angular motion system for the simulation of missile dynamics. This paper describes the initial laboratory integration of the hardware-in-loop Simulation (HILS) for homing guided missile system. HILS facilities and methodology form an integrated system for transforming a preliminary guidance and control system design to flight software and hardware from initial launching till impact. FMS will be driven by the output of deterministic simulations and will replicate the time history of the command signals. This paper describes the motivation, the servo system, mechanical, and electronic subsystems, and control software and algorithms. Moreover, the software user interfaces for the FMS. Six-degrees-offreedom (6-DOF) flying body model is utilized in association with graphical user interface (GUI) for FMS.
\end{abstract}

\section{KEY WORDS}

Simulation, Hardware in the loop, Seeker

\footnotetext{
* Dr. , Dpt. of Radar And Guidance, Military Technical Collage , Cairo, Egypt

** Eng. , Dpt. of Radar And Guidance, Military Technical Collage , Cairo, Egypt

*** Professor, Dpt. of Radar And Guidance, Military Technical Collage, Cairo, Egypt
} 


\section{INTRODUCTION}

Guidance and control system design has undergone phenomenal change due to the modern warfare tactics employed with the advent of computer and microprocessor technology. This sophistication of warfare tactics demands more research and development in the embedded software with the application of superior model and intelligent tools. Use of optimal estimators to replace conventional low pass filters is the current trend since more information about vehicle dynamics and noise covariance is available to the designer due to the increased computational power offered by present day processing technology in terms of speed and precision [1].

Design of more advanced guidance laws has become possible due to the availability of more accurate and complete information about vehicle states. The increased brain power resident in embedded processors has necessitated the use of even more superior and efficient validation methodologies with practical demonstration of engagement scenario. This is available in today's simulation computers by high speed hardware logics with inherent parallelism and super fast communication speeds. Flight motion simulators (FMS) along with hardware actuators and associated electronics are the necessary elements of the simulation test bed for validating the guidance and control system with actual hardware and flight software. This sophisticated setup helps to update and freeze the complex nonlinear guidance and control systems which are otherwise dependent mostly on linear design methodology.

Hardware-in-loop simulation (HILS) is a must step towards an advanced aerospace flight guidance and control system design. HILS is used for system design verification, quick flight software generation, verification and validation, system integration, pre-flight and post-flight analysis and demonstration of system performance. HILS started with non-real-time (NRT) environment, evolving into a real-time (RT) plant model with the availability of powerful simulation computers. Uncertainty in the model is one of the major hindrances for finalizing the software design. Flight systems hardware like sensors, actuators, onboard computer, engines with the thrust frame, other fin assemblies and various seeker systems are introduced directly in HILS to minimize the uncertainty.

Introduction of previously mentioned hardware along with sophisticated instrumentation has helped in performance evaluation of the flight systems in a more realistic scenario. Robustness studies are also simulated in HILS for demonstrating the uncertainties and unmodeled dynamics of the guidance and control software/hardware system design by stressing it to various disturbances [2].

This paper proposed an in progress investigation on the hardware in loop simulation (HILS) for semi-active homing guidance and control system. To accomplish this, a 6DOF flight simulation model for the missile system of concern is carried out. Dynamical characterizations of the subsystems are figured out. Hardware in-loop simulation for missile system is introduced for system analysis and development. Hardware/software 
integration along with interfacing of various components constitutes the simulation loop is presented.

\section{System Description}

The system of concern is a semi active homing system. The semi-active homing guidance is based on the principle of utilizing the electromagnetic wave reflection but there is no missile-borne radar transmitter. There is only a receiver and the missile is designed to home on the reflected energy from the target during its flight, and due to ground radar that illuminates the target. That is, the target is illuminated by tracking radar at the launching site or other control point as shown in Fig.1. Using this reflected system energy from the target the missile formulates its own correction signals. However, the semi-active homing uses reflection from the target as the illuminator platform and weapon receiver are not co-located, and consequently the returning echo follows a path different from that of incident to the target. Due to different reasons, the target may not reflect energy efficiently in the direction of the missile, and consequently it may lose the target entirely, resulting in a missed intercept. This disadvantage is compensated for by the ability to use greater power and more diverse frequency ranges in the illuminator.

\section{Missile Model}

The missile examined in this work is a semi active homing guided missile. The missile is steered in space following the proportional navigation guidance method. An on-board guidance kit is utilized to generate the guidance commands. The missile is aerodynamically controlled with an acceleration control autopilot to steer the missile while skid-to-turn (STT) control policy is utilized. The STT steering policy requires two identical lateral (pitch and yaw) autopilots to control the missile attitude while a roll autopilot performs attitude stabilization in the maneuver plane. A roll position controller is utilized to keep an adequate roll damping [3].

The missile flies in space under the effect of thrust, weight, and aerodynamic forces. The action of these forces has a certain effect on the shape of the missile trajectory. The change of missile velocity $\left(\overline{\mathrm{V}}_{\mathrm{m}}\right)$ direction is performed with the help of aerodynamic forces in the atmosphere.

The Aerodynamic force is usually distributed into axes of the velocity coordinate system, which are related to the direction of the missile motion. The components of this force are resolved along the missile body axes as $\mathrm{F}_{\mathrm{xa}}, \mathrm{F}_{\mathrm{ya}}$, and $\mathrm{F}_{\mathrm{za}}$. These forces create aerodynamic moments owing to the fact that they do not pass through the missile center of gravity. The aerodynamic moment components around the missile body axes are $\mathrm{M}_{\mathrm{xa}}, \mathrm{M}_{\mathrm{ya}}$, and $\mathrm{M}_{\mathrm{za}}$. In case of thrust misalignment, a thrust moment will be created and should be taken into consideration.

\section{Guidance System Simulation}


The simulation process of the missile flight path is adopted in a 6 DOF model where a series of structured modules are developed. These modules are written in a computer code under MATLAB environment and developed to solve the simulation process. The stepwise algorithm describing the scenario of missile flight simulation flowchart is shown in Fig.3. . The integration step is varying according to the flight conditions such that the accuracy is increased. In addition, the simulation program is terminated if the time exceeds a preset final time, the missile hits the ground, the missile hits the target, or if the missile starts to fly away from the target. The missile and target states (position, velocity, and acceleration), guidance system parameters, control fin drive, and the inertial sensors of the autopilot should be initialized in addition to the initial elevation and azimuth launch angles.

Two controllers are utilized to steer and stabilized the missile motion in space via controlling both fins (attitude/attitude rate controller) and wings (acceleration controller). The fins control changes its mode of operation when the missile completes the boost phase and enters the sustain portion of its flight. During boost phase, the fin control system is designed to keep and stabilize the initial missile attitude. During the sustain phase, it will minimize the missile turning rate and constrains the angle of attack.

The wing control system is an acceleration control autopilot designed to achieve a translational motion of the missile on which the wings are located near its center of mass. However, a turning motion results because the effective wing hinge line does not coincide exactly with the center of mass. This motion is sensed by the inertial sensors strapped down on-board the missile that are partially constitute the autopilot. Consequently, fin control system steers the missile in space while driving the attitude rate to zero. In other words, those two controllers are heavily coupled through the body dynamics as shown in Fig. 2. .To relax the coupling terms the system of concern is rollstabilized one.

The previously described missile autopilot and the presented 6-DOF model associated with the dynamics of the inertial sensors are considered in the code development. Moreover, the aerodynamic uncertainties, flight parameters variation and wind guest are carried out in the code to be quiet close to realistic systems.

\section{HILS System Components}

The HILS system consists of three components: simulation model, control system, and I/O interface cards

In the system of concern, the same 6-DOF simulation program is used but due to using real signals some changes occurs in the system gains and the simulation time step to insure that the system will operate in the real time simulation.

\section{- I/O Interface Cards}


In I/O hardware interfacing PC data acquisition card (DAQ-2206) is used. DAQ-2206 is an advanced data acquisition card based on the 32-bit $\mathrm{PCl}$ architecture. High performance design and the state-of-the -art technology make this card idea for data logging and signal analysis application in media, process control, etc.

DAQ-2206 is an advanced data acquisition card provides many advanced features, this card has 32-bit PCl-Bus plug and play and up to 64 signal-ended input or 32 differential input, mixing of using SE and DI analog signal sources, also this card has 512 analog input channel gain queue configuration size. DAQ-2206 16-bit analog input resolution with sampling rate up to $250 \mathrm{KHz}$., DAQ-2206 is Programmable gain bipolar/unipolar analog input.

\section{- The Control System}

To control the motor motion using MOTIONLINK software program there are three loops have to be considered: current loop, velocity loop, and position loop.

\section{HILS System}

The objective of this study is to integrate typical missile seeker in hardware in loop simulation environment for R\&D. The output video signal from the seeker is acquired instead of the simulated seeker model in the 6-DOF simulation program. A movable RF source is used to simulate the target motion as in Fig. 3. . Currently for safety precautions and obvious reasons, the target motion is hardware simulated by invoking a generated hardware signal from a signal generator to simulate an acquired target signal from the RF seeker.

The necessary signal conditioning and interfacing is carried out to facilitate the integration with the 6-DOF simulation model to generate the missile guidance commands and steer the missile. The instantaneous missile response due to both outer guidance loop and the inner autopilot dynamical loop is demonstrated on a single axis turn table utilized during the build up of the experimental setup.

Table1 describes briefly the major components used to accomplish the HILS system setup. Various linear controllers have been designed and tested based on PI, PD, PID and PP control techniques to derive the DDR motor as a test bed to mount the missile radio seeker.

Table 1. HILS system components 
Proceeding of the 12-th ASAT Conference, 29-31 May 2007

GUD-06

\begin{tabular}{|c|c|c|}
\hline Hardware & Missile seeker & $\begin{array}{c}\text { Semi active seeker with } \\
\text { external power supplies }\end{array}$ \\
\hline $\begin{array}{c}\text { I/O Card and Signal } \\
\text { Interface }\end{array}$ & $\begin{array}{c}\text { PC data acquisition } \\
\text { card }\end{array}$ & Adlink-DAQ-2206 \\
\hline \multirow{2}{*}{ Turning Table } & Motor & Direct Drive Rotary Motor \\
\cline { 2 - 3 } & Digital Controller/ & Driver \\
\cline { 2 - 3 } & GUI Software & $\begin{array}{c}\text { SEload the designed controller } \\
\text { parameters to the control } \\
\text { system }\end{array}$ \\
\hline Simulation Model & 6DOF model & MATLAB platform \\
\hline Target & RF source & H band \\
\hline
\end{tabular}

\section{Simulation Results}

This section is devoted to evaluate the structure of the 6DOF model via numerical implementation. Toward this objective different engagement scenarios with different target maneuvers are considered in the form of case studies. And are summarized in table 2

Table 2 . Different missile-target engagement scenarios

\begin{tabular}{|c|c|c|c|c|c|c|c|c|c|c|c|c|}
\hline \multirow{2}{*}{ case } & \multicolumn{3}{|c|}{ Target velocity [m/s] } & \multicolumn{3}{|c|}{ Target position $[\mathrm{Km}]$} & \multicolumn{5}{|c|}{ Target Maneuver [m/s $\left.\mathrm{s}^{2}\right]$} & Miss \\
\cline { 2 - 13 } & $\mathrm{v}_{\mathrm{t}_{\mathrm{x}}}$ & $\mathrm{v}_{\mathrm{t}_{\mathrm{y}}}$ & $\mathrm{v}_{\mathrm{t}_{\mathrm{z}}}$ & $\mathrm{x}_{\mathrm{t}}$ & $\mathrm{y}_{\mathrm{t}}$ & $\mathrm{z}_{\mathrm{t}}$ & $\mathrm{a}_{\mathrm{x}}$ & $\mathrm{a}_{\mathrm{y}}$ & $\mathrm{a}_{\mathrm{z}}$ & $\begin{array}{c}\text { Start } \\
\text { time }\end{array}$ & $\begin{array}{c}\Delta \mathrm{t} \\
{[\mathrm{sec}]}\end{array}$ & {$[\mathrm{m}]$} \\
\hline 1 & -400 & -350 & 0 & 20 & 17 & 4 & 20 & -15 & 10 & 10 & 5 & 1.37 \\
\hline 2 & -400 & -350 & 0 & 20 & 17 & 4 & 20 & 15 & 10 & 10 & 5 & 0.08 \\
\hline 3 & 100 & 250 & 0 & 6 & 1 & 2 & 0 & 0 & 0 & - & - & 1.42 \\
\hline 4 & -250 & 200 & 0 & 16 & 13 & 2.6 & -10 & -40 & 0 & 3 & 10 & 182 \\
\hline 5 & -250 & 200 & 0 & 6 & 3 & 2.6 & -10 & -40 & 10 & 5 & 4 & 414 \\
\hline 6 & -100 & -250 & 0 & 6 & 1 & 2 & 30 & -25 & 10 & 5 & 2 & 14.5 \\
\hline 7 & -100 & -250 & 0 & 6 & 1 & 2 & 20 & -15 & 10 & 4 & 2 & 1.41 \\
\hline 8 & -100 & -250 & 0 & 6 & 1 & 2 & 30 & -25 & 10 & 4 & 2 & 1.89 \\
\hline 9 & -100 & -250 & 0 & 6 & 1 & 2 & 30 & -25 & 10 & 8 & 2 & 50.74 \\
\hline 10 & -100 & -250 & 0 & 6 & 1 & 2 & 30 & -25 & 10 & 7 & 2 & 85.4 \\
\hline
\end{tabular}


In case 1 - for example - Consider a maneuvering target, making its maneuver after 10 seconds from missile launch and last for 5 seconds. The engagement scenario is shown in Fig. 6 in which a missile successfully hit the target within an acceptable miss distance.

\section{HILS Experimental Results}

This section is devoted to evaluate the structure of the HILS for the semi-active homing guidance system. The interior signals and waveforms resulting from the HIL experiments are considered in the form of case studies.

\section{- Case Study 1}

In this case study the initial target position was fed to the 6DOF model and the target maneuver is simulated from the hardware input generated signal. The target is hit and the missile-target engagement scenario is shown in Fig.7 also the generated LOS signal and side slip angle and the turn table feed back are shown in Fig.8,9,10 And for consistency another angle of attack profile for case study 2 are shown in the figures $11-14$

\section{Conclusions}

This paper described the development and initial laboratory integration of the (HILS) which form a well integrated system for transforming a preliminary guidance and control system design to flight software and hardware from initial launching till impact. The paper described the motivation, the servo system, mechanical, and electronic subsystems, control software and algorithms, and the software user interface for the HILS. Six-degrees-of- freedom (6DOF) flying body model was realized. 


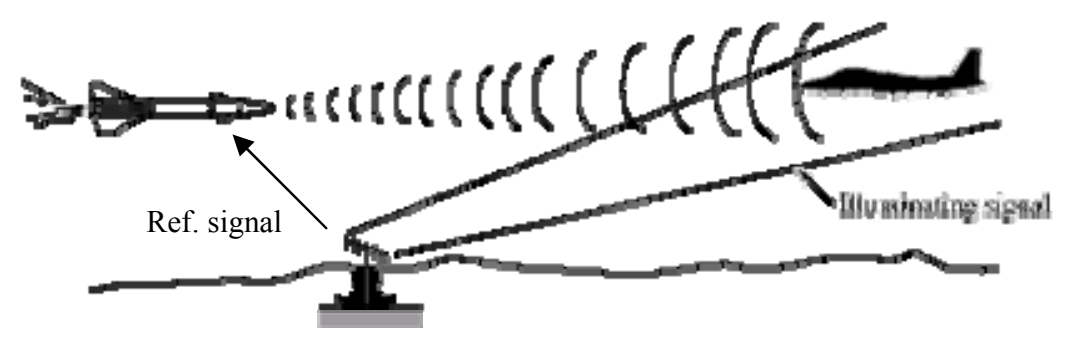

Fig.1. semi-active homing system

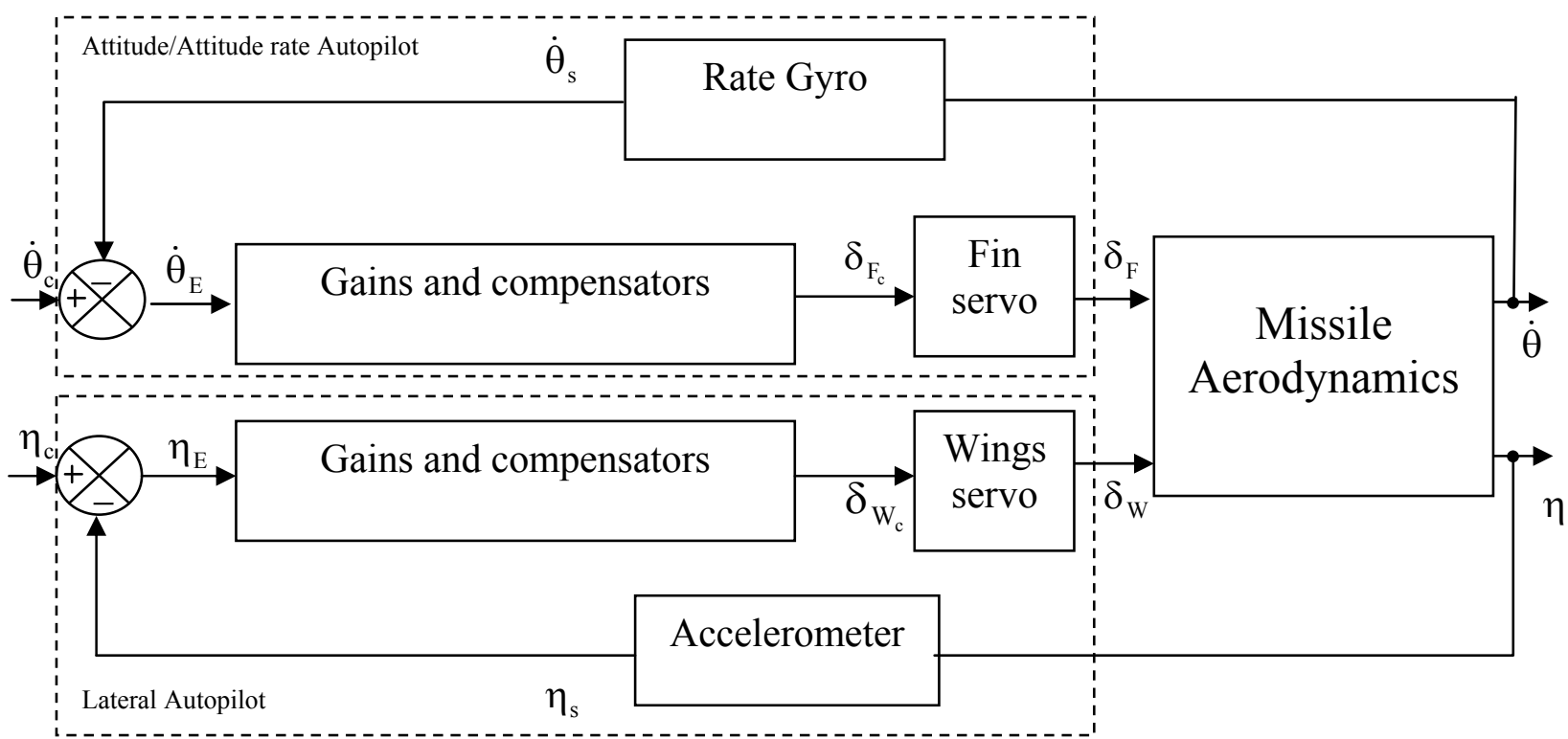

Fig.2. Autopilot structure 


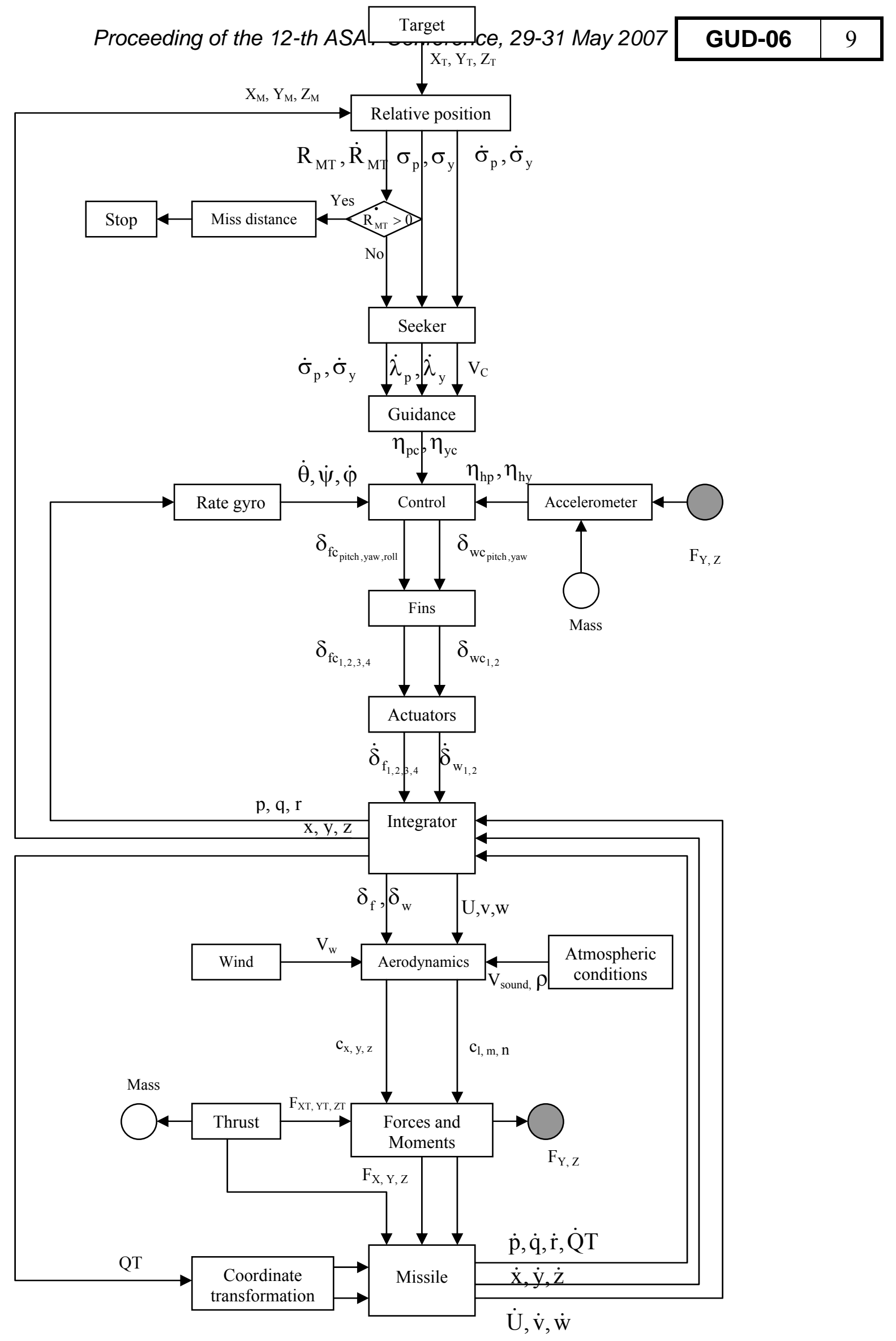

Fig.3. Flowchart of the 6DOF simulation program 
Proceeding of the 12-th ASAT Conference, 29-31 May 2007

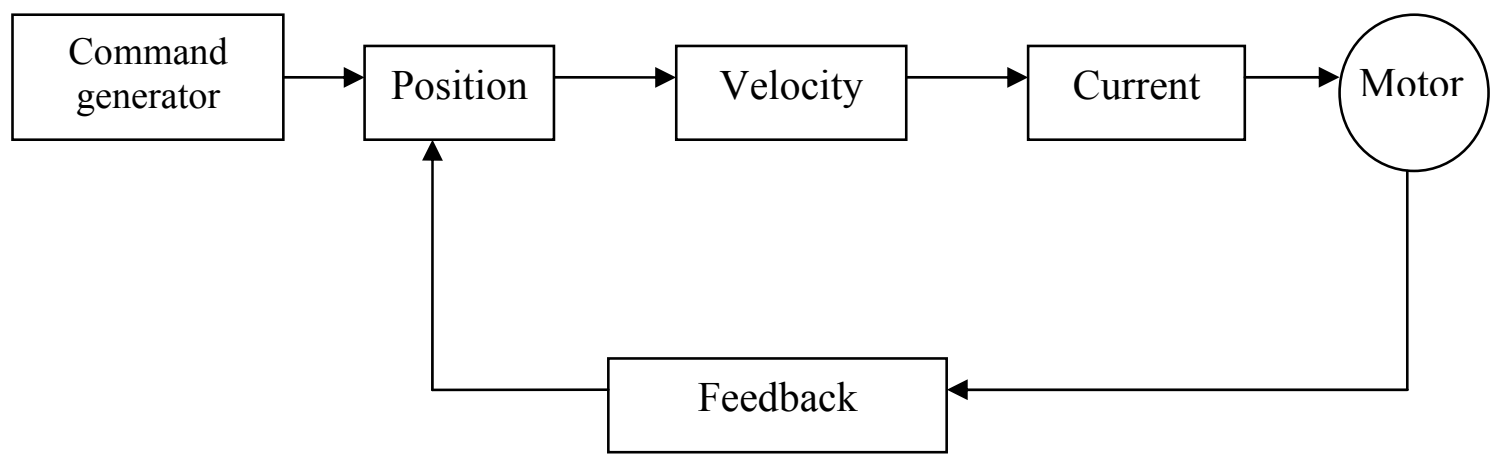

Fig.4. The MOTIONLINK Block Diagram

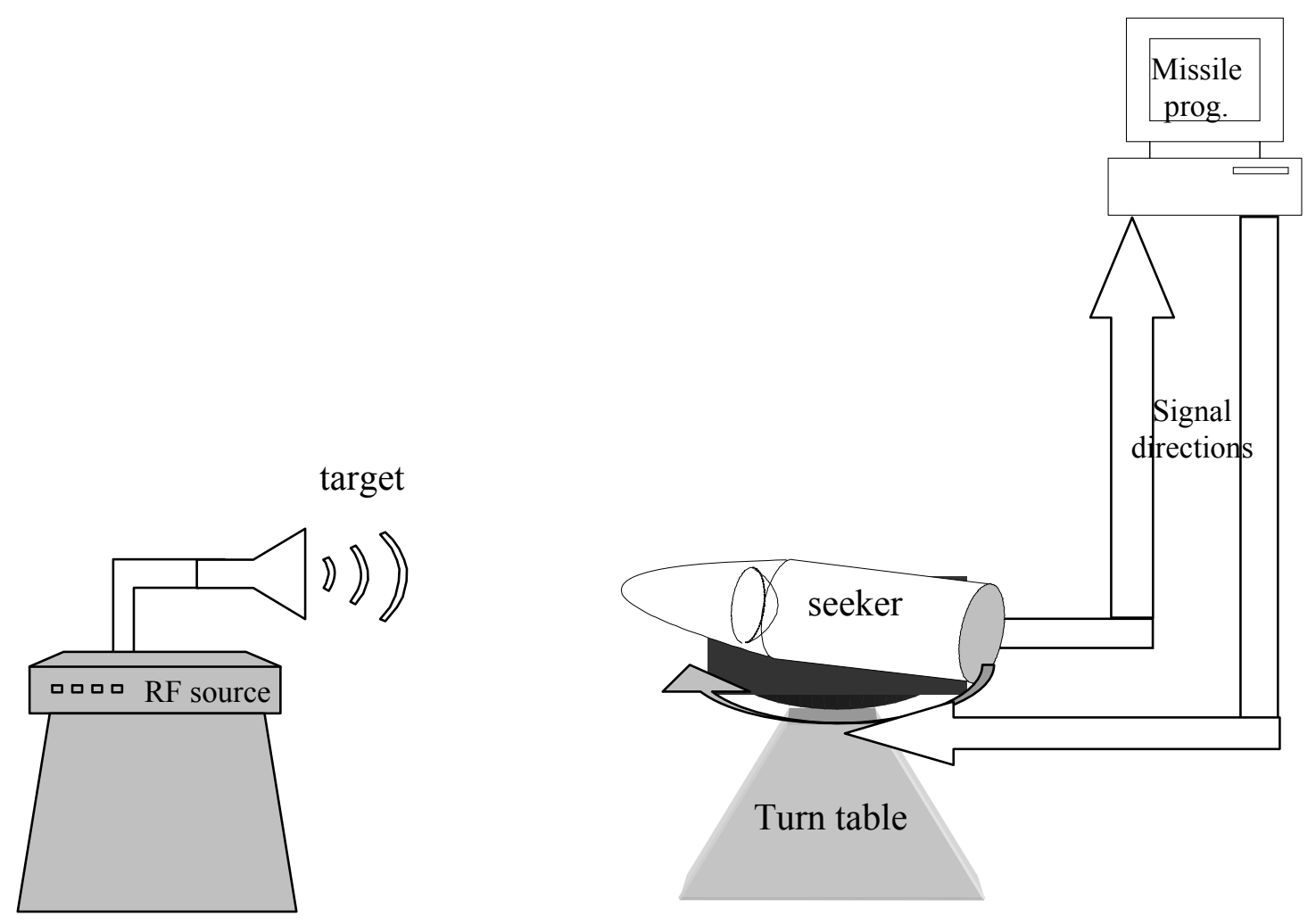

Fig .5. HILS system 


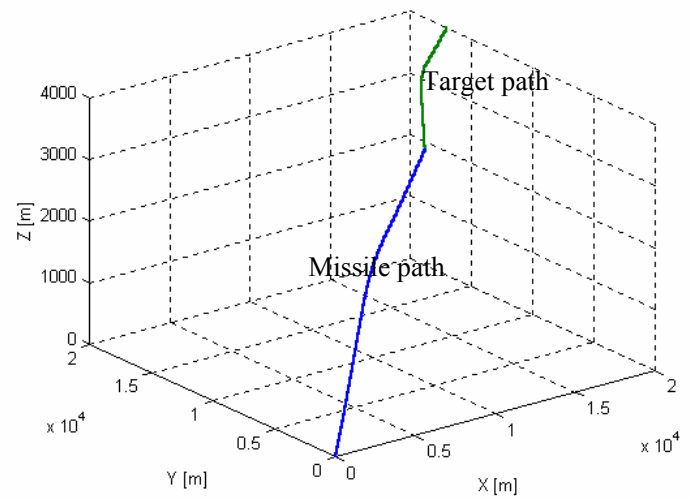

Fig.6. Missile -Target engagement scenario for case 1

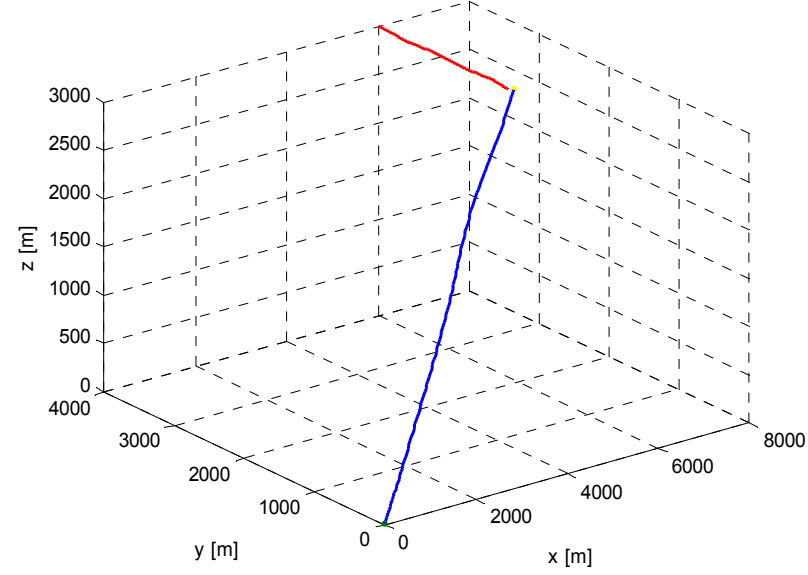

Fig.7. msl., tgt. trajectory for case study 1

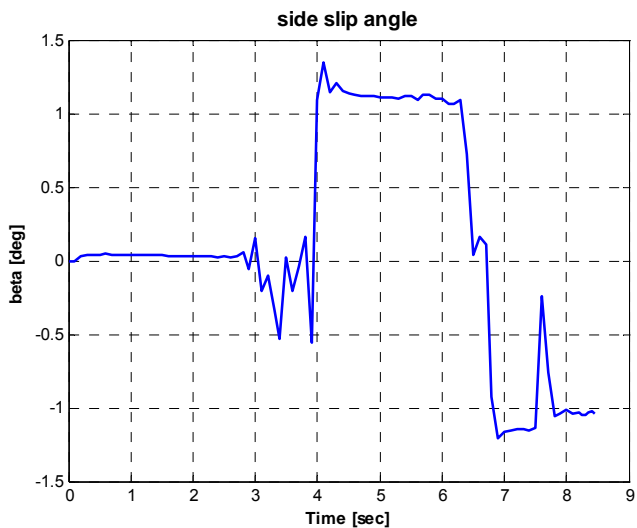

Fig.9. side slip angle profile for case study 1 Fig.10. turn table feedback profile for case study 1 


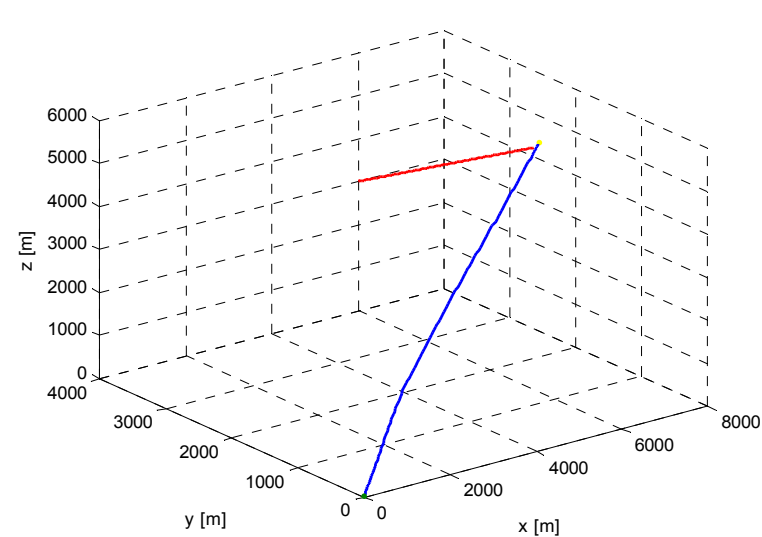

Fig.11. msl., tgt. trajectory for case study ${ }^{r}$

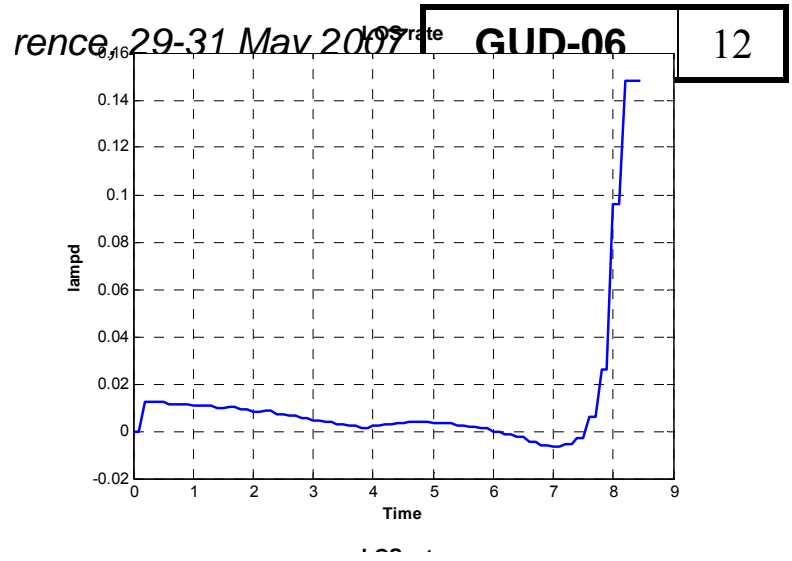

Fig.12. generated LOS signal for case study 2
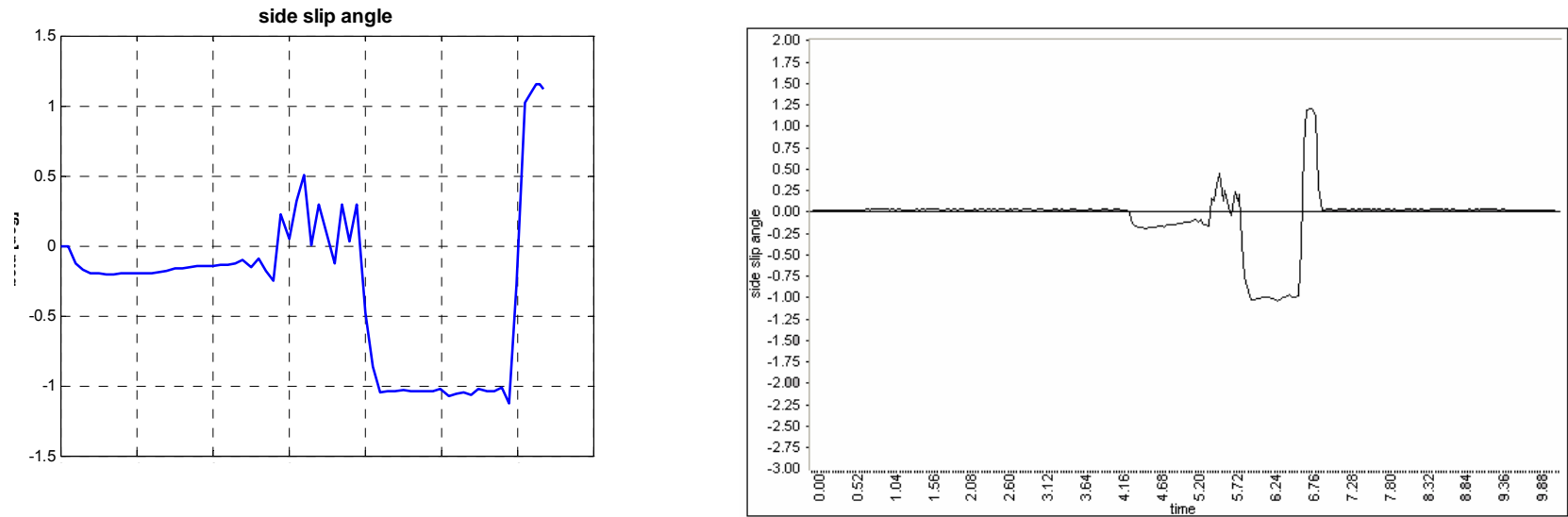

Fig.13. side slip angle profile for case study 2

Fig.14. turn table feedback profile for case study 2

\section{REFERENCES}

[1] Garnell P., and East D. J.; "Guided Weapon Control Systems", Pergamon Press, Oxford, England, 1977.

[2] Miroslav K. Cosic, et.al. "Design and Implementation of a HILS for a Semi-

Automatic Guided Missile System", 1999.

[3] Etkin, B.:" Dynamics of Atmospheric Flight", Inc., New York, 1972.

[4] A. M. Kamel, "Performance Enhancement of A Semiactive homing Radio Guided Missile", M.Sc. thesis, MTC, Cairo, 2002.

[5] Etkin B. and L. Reid; "Dynamics of Flight Stability and Control", Wiley, 1996.

[6] J. Schaffnit R. Isermann and S. Sinsel. "Hardware-in-the-loop simulation for design and testing of engine", 1999. 